\title{
Palatogingival Groove: An Innocuous Culprit of Periodontal Lesion
}

\author{
${ }^{1}$ Vanita Kashyap, ${ }^{2}$ Mala Dixit Baburaj
}

\section{ABSTRACT}

Palatogingival grooves are morphological defects, which are found most frequently in maxillary anterior teeth and are a predisposing factor for periodontal disease. They are easily overlooked as etiologic factors, as these grooves are covered by periodontal tissues. A palatogingival groove may serve as a pathway for the development of a periodontal lesion.

This case report presents successful management of a maxillary lateral incisor with an associated palatogingival groove and deep periodontal pocket. The clinical examination at 1 year revealed shallow residual probing depth.

Keywords: Palatogingival groove, Maxillary lateral incisor, Osseous defect, Regenerative periodontal therapy.

How to cite this article: Kashyap V, Baburaj MD. Palatogingival Groove: An Innocuous Culprit of Periodontal Lesion. J Contemp Dent 2015;5(1):38-39.

\section{Source of support: Nil}

Conflict of interest: None

\section{INTRODUCTION}

Palatogingival grooves ${ }^{1}$ have also been termed palatal radicular grooves, distolingual grooves, radicular grooves, and vertical development grooves. The groove was first mentioned in a dental anatomy text in 1917, later described by Zeisz Nuckolin in $1949 .^{2}$ Kovacs in 1971 called it as a 'syndesmo-corono radicular' tooth. ${ }^{3}$

It is a mild developmental malformation that occurs in the lingual aspect of maxillary incisors. This malformation starts near the cingulum and runs in an apical direction for varying lengths up to the entire length of root. This anomaly is said to represent an infolding of the enamel organ and epithelial sheath of Hertwig, ${ }^{4}$ where as other workers claim this to be a resultant attempt of the body to form another root on the affected tooth. ${ }^{5}$

Kogon in 1986 examined 3168 extracted maxillary central and lateral incisors. Palatogingival grooves found on $4.6 \%$ of maxillary incisors $(3.4 \%$ maxillary

\footnotetext{
${ }^{1}$ Postgraduate Student, ${ }^{2}$ Professor and Head

1,2Department of Periodontics, Nair Hospital Dental College Mumbai, Maharashtra, India
}

Corresponding Author: Vanita Kashyap, Postgraduate Student Department of Periodontics, Nair Hospital Dental College, Mumbai Maharashtra, India, Phone: 02223082714, e-mail: vanita1086@ gmail.com centrals and $5.6 \%$ on maxillary lateral incisors) $54 \%$ of palatogingival grooves terminated on the root with $43 \%$ of those extending less than $5 \mathrm{~mm}$ and $47 \%$ extending 6 to $10 \mathrm{~mm} .{ }^{6}$ Goon in 1991 classified radicular lingual groves as simple and complex. Simple radicular lingual groves do not have communication with the pulp and terminate at the cementoenamel junction. The complex radicular lingual grooves have direct communication with the pulp and extend to various lengths along the root. $^{7}$ It is the funnel shaped appearance which forms a niche for bacterial plaque and calculus accumulation making it difficult for the patient as well as professional to clean it properly. Inflammation may thus, develop in the periodontal tissue adjacent to the groove leading to the detachment of junctional epithelium, periodontal destruction, pocket formation and alveolar bone loss. ${ }^{5}$

\section{CASE REPORT}

A female aged 30 years reported to the Department of Periodontics, Nair Hospital Dental College, with the chief complaint of bleeding from upper font teeth region since 3 months. On intraoral examination, gingival color was reddish, gingival contour showed rolled out marginal gingiva and interdental papillae was flattened, consistency was soft and edematous and surface texture was smooth because of loss of stippling in the upper anterior region. Periodontal examination revealed periodontal pocket of $10 \mathrm{~mm}$ with respect to right maxillary lateral incisor (Fig. 1A). On further clinical examination of the palatal surface of tooth, a fine palatogingival groove was noticed which started at the cingulum and travelled apically and laterally. Pulp vitality revealed that the tooth was vital. Intraoral periapical radiograph showed interdental bone loss distal to right maxillary lateral incisor (Fig. 1B). The phase I periodontal therapy consisted of oral hygiene instructions and scaling and root planing. After re-evaluation of phase I therapy, a decision to perform periodontal surgery in the upper anterior region was taken.

Two percent lidocaine hydrochloride with 1:200000 epinephrine was administered. After flap elevation, root surfaces were scaled and planed. Saucerisation of the groove by grinding it out to its depth using a small round diamond bur was performed (Fig. 2A). This was followed by conditioning the groove with $10 \%$ polyacrylic 
acid and sealing the defect with flowable composite (Fig. 2B). Then the flap was approximated and sutured with silk 3-0 sutures. Postoperative instructions and medications were given-capsule amoxicillin $500 \mathrm{mg}$ tid, tablet ibuprofen tid for 5 days and mouthwash containing $0.2 \%$ chlorhexidine gluconate twice a day for 2 weeks. Sutures were removed after a week.

\section{RESULTS}

There was no postoperative complications, and the patient was re-evaluated at 1, 3, 6, 9 and 12 months, and after 12 months, the healing was complete with gingiva being healthy, palatogingival groove was absent (Fig. 3).

\section{DISCUSSION}

The predominance of palatogingival groove in maxillary lateral incisor is due to an undesirable position of the lateral incisor during the period of maxillary growth. The
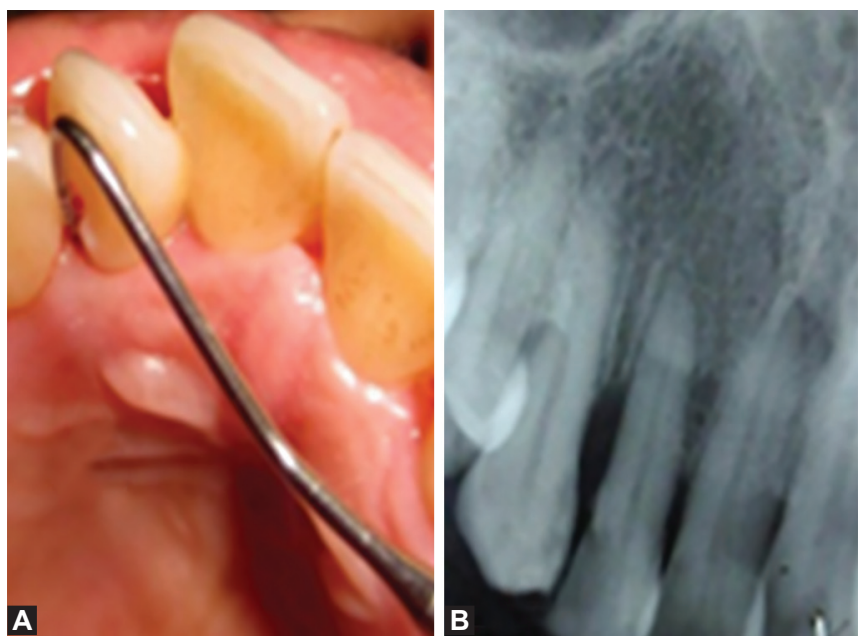

Figs 1A and B: (A) Periodontal pocket of $10 \mathrm{~mm}$ with respect to right maxillary lateral incisor and (B) intraoral periapical radiograph showed interdental bone loss
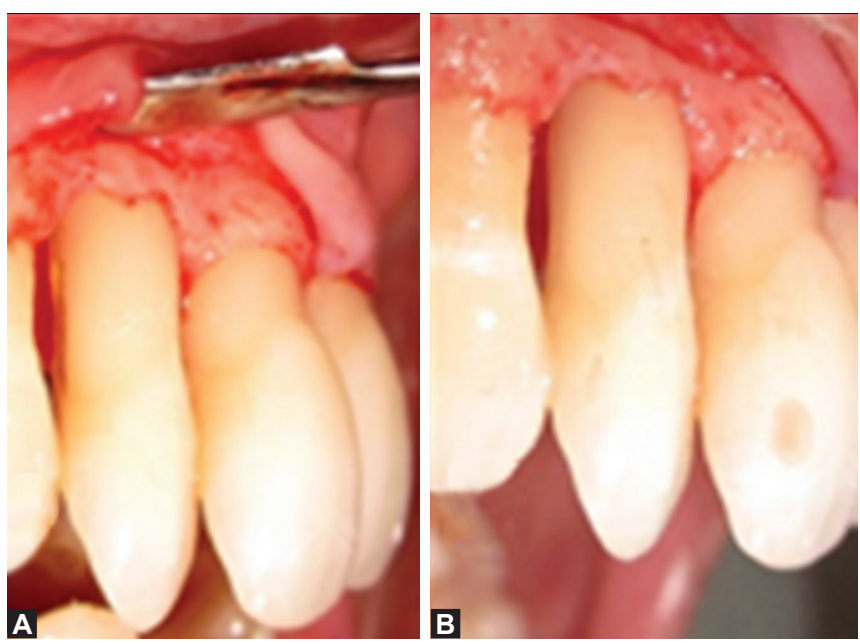

Figs 2A and B: (A) Palatogingival groove visible on the distal surface after flap reflection and (B) the defect sealed with flowable composite

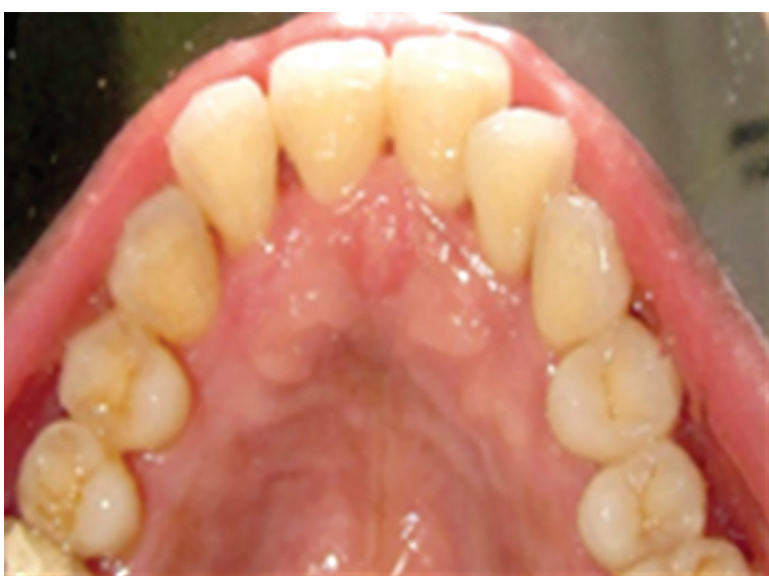

Fig. 3: After 12 months gingiva is healthy, palatogingival groove is absent

tooth although still a germ, becomes surrounded by the central incisors, canine and first premolar that are in a more advanced phase of dental development. Mineralization of the crown of the maxillary lateral incisor starts later compared with other teeth, making this germ, under these condition highly susceptible to folding.

The grooves can be eliminated by odontoplasty in the case of shallow ones or by restoring with amalgam, composite or glass ionomer cements. ${ }^{8}$ In our case, saucerization of the groove was carried out followed by restoration with flowable composite because the groove was deep.

\section{CONCLUSION}

We should have an eye to recognize the distruction caused by palatogingival groove early in order to save the patient from periodontal destruction.

\section{REFERENCES}

1. Lee KW, Lee EC, Poon KY. Palatogingival groove in maxillary incisors. Br Dent J 1968;124(1):14-18.

2. Zeisz RC, Nuckolin J. Dental Anatomy. St Louis, CV Mosby Co 1949. p. 65.

3. Kovacs J. A systematic description of dental roots. Dahlberg AA. Dental morphology and evolution. University of Chicago Press, Chicago, 1971;211-256.

4. Walker RT, Jones GJC. The palatogingival groove and pulpitis: a case report. Int Endod J 1983;16(1):33-34.

5. Kerezoudis NP, Siskos GJ, Tsatsas V. Bilateral buccalradicular groove in maxillary incisor: case report. Int Endod J 2003; 36(12):898-906.

6. Kogan SL. The prevalence, location and conformation of palato-radicular grooves in maxillary incisors. J Periodontol 1986;57:2312.

7. Goon WW, Carpenter WM, Brace NM, Ahlfeld RJ. Complex facial radicular groove in a maxillary lateral incisor. J Endod 1991;17(5):244-248.

8. Schafer E, Cankay R, Ott K. Malformations in maxillary incisors: case report of radicular palatal groove. Endod Dent Traumatol 2000;16(3):132-137. 